\title{
Aspirin for Primary and Secondary Prevention of Cardiovascular Disease: Time to Stop?
}

\author{
John G. F. Cleland ${ }^{1} \odot$ \\ ${ }^{1}$ Robertson Centre for Biostatistics, Institute of Health and Wellbeing, \\ University of Glasgow, Glasgow, United Kingdom \\ Thromb Haemost 2022;122:311-314.
}

Address for correspondence John G. F. Cleland, MD, PhD, Robertson Centre for Biostatistics and Glasgow Clinical Trials Unit, University of Glasgow G12 8QQ, United Kingdom (e-mail: john.cleland@glasgow.ac.uk).
Recent trials suggest that aspirin does not reduce cardiovascular events or increase longevity in people who are not known to have cardiovascular disease, ${ }^{1}$ leading to draft recommendations in the United States against the use of aspirin for primary prevention in people aged $>60$ years. $^{2}$ This will cause much dismay to those with a dogmatic belief in aspirin's benefits but, perhaps, much rejoicing amongst patients who have one less pill thrust upon them. ${ }^{3-5}$ The failure of aspirin for primary prevention should now lead to a re-examination of the evidence for aspirin for secondary prevention. ${ }^{1,6-11}$

Calderone et $\mathrm{al}^{12}$ provide an updated meta-analysis of 21 randomized trials of aspirin for the primary prevention of cardiovascular events, including 173,810 patients and almost one million patient-years of follow-up. Of the 21 trials, 16 were placebo-controlled, including a recent trial of an aspirin-containing polypill. ${ }^{13}$ An effective intervention does not require a large trial to show benefit, but confirming that an intervention has no effect does. The authors suggest that aspirin might reduce the risk of myocardial infarction and transient ischemic attacks (TIAs), but not stroke, and provide no evidence that this translates into a reduction in chronic disability. If the reduction in nonfatal events was real and these events were important, then they should translate into a reduction in mortality. ${ }^{6}$ However, aspirin did not reduce all-cause, cardiovascular, or noncardiovascular mortality. Most myocardial and cerebral vascular events are missed. ${ }^{6}$ Less than a third of myocardial infarctions and one-fifth of cerebral vascular events are clinically obvious. ${ }^{14-16}$ Many patients with a myocardial or cerebral infarction will die before a clinical diagnosis is possible. ${ }^{17}$ The failure of aspirin to reduce mortality suggests that it might simply change how events present rather than prevent them.

Calderone et al also report that aspirin increased the risk of major bleeding events by approximately 50\%; use of lower doses did not diminish this risk. The authors hypothesize that the effects on vascular events and risk of bleeding may vary

received

November 14, 2021

accepted

November 15, 2021

published online

January 20, 2022 with age, with the balance being less favorable in older people, even though they are more likely to have unrecognized coronary artery disease. Indeed, they found an interaction between age and mortality, with an excess mortality of approximately $10 \%$ in those aged $>70$ years, but neither an interaction between age and vascular events nor, surprisingly, the risk of major bleeding.

For people aged $<65$ years, death (47 per 1,000 people over 5 years without aspirin) was at least twice as common as myocardial infarction (22 events), stroke (16 events), or major bleeds (18 events). If 1,000 people aged $<65$ years took aspirin for 5 years, the authors predicted that this would lead to two fewer deaths, one cardiovascular and one noncardiovascular, about three fewer myocardial infarctions, and one less stroke, but one more intracerebral bleed and nine more major bleeding events.. Even if the estimated effect of aspirin is true, is it worth it? The great majority of events would not be prevented. Do we not have more effective interventions to consider, such as antihypertensive and lipid-lowering agents, smoking cessation, and a healthy lifestyle?

For people aged $\geq 65$ years, death (62 per 1,000 people over 5 years without aspirin) was more than twice as common as myocardial infarction (19 events), stroke (23 events), or major bleeds ( 29 events). If 1,000 people aged $\geq 65$ years took aspirin for 5 years, the authors predicted that this would have no effect on cardiovascular death but result in five additional noncardiovascular deaths, four more intracerebral bleeds, and seven more major bleeding events, although it might lead to three fewer myocardial infarctions and two fewer strokes. Thus, despite being at higher risk of both cardiovascular disease and cancer, the balance of risk and benefit of primary prevention for aspirin looks rather unfavorable for people aged $\geq 65$ years.

These results place further doubt on the value of longterm aspirin prophylaxis for secondary prevention. Many older people will have undiagnosed atherosclerotic disease, (c) 2022. Thieme. All rights reserved. Georg Thieme Verlag KG, Rüdigerstraße 14 , 70469 Stuttgart, Germany
DOI https://doi.org/ 10.1055/s-0041-1740639. ISSN 0340-6245. 
for whom this analysis suggests that the harms outweigh the benefits. Clinically overt hemorrhage may only be the tip of an iceberg of aspirin-related problems. Aspirin might also increase the rate of end-stage renal disease and microvascular cerebral hemorrhage, while increased rates of protonpump inhibitor use may be fuelling an epidemic of iron deficiency. ${ }^{6,18}$

Why do so many doctors believe that long-term aspirin for secondary prevention is effective? ${ }^{8}$ Historically, the most important reasons may be publication bias and meta-analyses of trials that appeared positive but only due to the inclusion of small, unrealistically positive trials. ${ }^{10,19}$ More recent versions of the secondary prevention meta-analysis have excluded trials which previously appeared to show that aspirin could achieve resurrection, but the damage that such bias creates to perceptions and guidelines is hard to reverse. $7,10,19$

A short course of aspirin after a vascular event does appear beneficial, as might an antibiotic for pneumonia. Just because a course of treatment is effective it does not mean it should be continued lifelong. A definitive trial, ISIS-2, showed that aspirin reduced recurrent infarction and mortality when given immediately after a myocardial infarction. ${ }^{20}$ The course of treatment was only 4 weeks but the legacy of that course of treatment lasted at least 10 years, despite the fact that most patients must have stopped taking aspirin after 4 weeks; after all, only $5 \%$ of patients in ISIS- ${ }^{21}$ were discharged on an antiplatelet agent and no intervening trial could have changed clinical practice. Also, if there was enough equipoise to have a placebo group in ISIS-2, then there was no valid argument for starting aspirin at the end of the 4-week double-blind period. Similarly, aspirin given immediately after a stroke/TIA for 6 to 12 weeks reduces the risk of recurrent stroke, disability, and death, but without evidence of benefit thereafter. ${ }^{22}$ There is little evidence that continuing aspirin beyond 12 weeks after a myocardial infarction or a stroke is beneficial ( $\mathbf{- F i g . 1} \mathbf{1}$ ).

The only substantial randomized, placebo-controlled, long-term trial of aspirin after a myocardial infarction at a dose of $<300 \mathrm{mg} /$ day exists only in the imagination of doctors. The long-term trials that do exist used much larger doses and showed no effect on mortality, or even a trend to excess $^{23}$ ( $\mathbf{- F i g . 1}$ ). Probably the strongest evidence for aspirin (dose $75 \mathrm{mg} /$ day) for secondary prevention comes from the SAPAT trial that, between 1985 and 1989, enrolled 2,035 patients diagnosed with angina by a primary care physician. ${ }^{24}$ This was before the widespread introduction of statins. The study found a significant reduction in the composite of myocardial infarction or sudden death (124 events on placebo compared with 81 on aspirin; $p=0.003$ ) with a similar trend for all-cause mortality (106 and 82 respectively; $p=0.103$ ). This is a slim amount of evidence upon which to make strong recommendations. These results also contrast with those of the largest, long-term secondary

\begin{tabular}{|c|c|c|c|c|c|c|c|c|c|c|c|c|c|c|}
\hline & & & & & & \multicolumn{2}{|c|}{ Randomised } & $\begin{array}{c}\mathbf{F U} \\
\text { (months) }\end{array}$ & \multicolumn{2}{|c|}{ CV Deaths } & \multicolumn{2}{|c|}{ Non-CV Deaths } & \multicolumn{2}{|c|}{ All-Cause Mortality } \\
\hline Trial & Year & Country & Prior Event & $\begin{array}{l}\text { Average Time } \\
\text { from Event to } \\
\text { Randomisation }\end{array}$ & $\begin{array}{l}\text { Aspirin } \\
\text { Dose }\end{array}$ & Placebo & Aspirin & & Placebo & Aspirin & Placebo & Aspirin & Placebo & Aspirin \\
\hline PARIS-I* & 1980 & USA/UK & Post-MI & $>6$ months & $972 \mathrm{mg}$ & 406 & $* 405$ & 41 & 45 & $* 37$ & 7 & *5 & 52 & $* 43$ \\
\hline AMIS & 1980 & USA & Post-MI & $>12$ months & $1,000 \mathrm{mg}$ & 2257 & 2267 & 38 & 181 & 197 & 38 & 48 & 219 & 245 \\
\hline SAPAT & 1992 & Sweden & Angina & Prior MI excluded & $75 \mathrm{mg}$ & 1026 & 1009 & 50 & 70 & 51 & 36 & 31 & 106 & 82 \\
\hline \multicolumn{6}{|r|}{ Total } & 3689 & 3681 & $>40$ & $\begin{array}{r}296 \\
(8.0 \%)\end{array}$ & $\begin{array}{r}285 \\
(7.7 \%) \\
\end{array}$ & $\begin{array}{r}81 \\
(2.2 \%) \\
\end{array}$ & $\begin{array}{r}84 \\
(2.3 \%) \\
\end{array}$ & $\begin{array}{r}377 \\
(10.2 \%)\end{array}$ & $\begin{array}{r}370 \\
(10.0 \%) \\
\end{array}$ \\
\hline \multicolumn{6}{|c|}{ Effect of Aspirin } & & & & \multicolumn{2}{|c|}{$<1$ fewer/1,000pt-yr } & \multicolumn{2}{|c|}{$<1$ fewer $/ 1,000$ pt-yr } & \multicolumn{2}{|c|}{$<1$ fewer $/ 1,000 \mathrm{pt}-\mathrm{yr}$} \\
\hline \multirow[t]{5}{*}{ CARDIFF-I $^{\sharp}$} & 1974 & UK & Post-MI & & $300 \mathrm{mg}$ & 560 & 566 & 12 & & & & & 61 & 47 \\
\hline & & & & $<4$ weeks & & 157 & 138 & & & & & & $15(9.6 \%)$ & $9(6.5 \%)$ \\
\hline & & & & 4-5 weeks & & 139 & 145 & & & & & & $24(17.3 \%$ & $13(9.0 \%)$ \\
\hline & & & & 6-13 weeks & & 136 & 150 & & & & & & $14(10.3 \%)$ & $15(10.0 \%)$ \\
\hline & & & & $>14$ weeks & & 128 & 133 & & & & & & $8(6.3 \%)$ & $10(7.5 \%)$ \\
\hline
\end{tabular}

*Randomisation was 2:1; accordingly, numbers in the aspirin group have been halved. \# CARDIFF-I trial suggested benefit only when aspirin was given within 6 weeks of myocardial infarction (MI). For references to trials see reference 6.

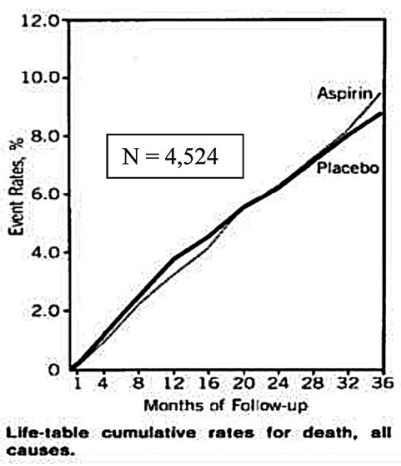

Fig. 1 All-cause mortality in the Aspirin Myocardial Infarction Study (AMIS), the largest trial of long-term aspirin administration both in terms of numbers of patients and events. The authors concluded "aspirin is not recommended for routine use in patients who have a survived an MI." Although the doses used are much higher than contemporary guidelines suggest, there is no substantial long-term, placebo-controlled trial of aspirin after myocardial infarction at a dose of $<300 \mathrm{mg} /$ day. There is no placebo-controlled trial of late-initiation, long-term aspirin after a cerebro-vascular event. 23 
prevention trial after myocardial infarction (AMIS; $n=4,524$; aspirin dose $1,000 \mathrm{mg} /$ day), which showed numerically more deaths on aspirin (245 deaths; $10.8 \%$ ) than on placebo (219 deaths; $9.7 \%){ }^{23}$ The largest long-term trial of aspirin after a stroke (UK TIA; $n=2,449$; aspirin dose $300 \mathrm{mg}$ or 1,200 $\mathrm{mg}$ /day) reported 119 strokes on placebo compared with 100 on aspirin $300 \mathrm{mg} /$ day and, respectively, 90 compared with 81 coronary events and 122 compared with 109 deaths. ${ }^{25}$ None of the differences in UK TIA were significant. Importantly, these trials were conducted before the era of effective treatments for hyperlipidemia, hypertension, and diabetes for which there is robust evidence of an effect on morbidity and mortality.

Aspirin, even at low doses, blocks the production of vasodilator prostaglandins that reduce endothelial platelet adhesion and have important effects on renal water and salt handling. ${ }^{6,26}$ P2Y12 inhibitors have more selective effects on platelet function but clopidogrel has only marginally greater effects on cardiovascular events compared with aspirin and no greater effect on mortality. ${ }^{27}$ The COMPASS trial did suggest that addition of rivaroxaban $2.5 \mathrm{mg}$ twice daily to aspirin $100 \mathrm{mg} /$ day might reduce both morbidity and mortality for patients with chronic atherosclerotic disease but created uncertainty over whether rivaroxaban alone might be as effective as the combination. ${ }^{28}$ Preconceptions about the efficacy of aspirin interfered with the design, duration, and interpretation of the effects of rivaroxaban monotherapy in the COMPASS trial.

Theoretical considerations also influence practice. Vascular occlusion is considered by many to be primarily a thrombotic event. However, thrombosis is usually secondary to plaque rupture, which may often be caused by hemorrhage from neovascular proliferation from the vasa vasorum ${ }^{6}$; a pathology akin to diabetic retinopathy. For a patient with an ulcerated plaque presenting with a vascular event, the risk of thrombosis is high and the net effect of a short course of aspirin is beneficial. For patients with plaque that is not ulcerated, the risk of hemorrhage may balance or outweigh the risk of thrombosis. ${ }^{6}$ Percutaneous vascular interventions will cause plaque disruption for which a course of antiplatelet therapy is warranted but we have no evidence that life-long therapy is required. Indeed, recent trials investigating de-escalation of antithrombotic therapy suggest that withdrawal may be possible or even advisable, although this should be substantiated by further research.

In conclusion, aspirin taken long-term may "give with one hand but take away with the other," leaving the individual only with indigestion, an increased risk of major bleeding, and other adverse consequences. However, there is good evidence that aspirin given for 4 to 12 weeks after a vascular event is beneficial; beyond that, surely we have better things to do for our patients and with our valuable time than prescribe aspirin.

\section{Conflict of Interest}

J.G.F.C. has received research funding and personal honoraria from Bayer Pharmaceuticals.

\section{References}

1 Raber I, McCarthy CP, Vaduganathan M, et al. The rise and fall of aspirin in the primary prevention of cardiovascular disease. Lancet 2019;393(10186):2155-2167

2 United States Preventive Services Task Force. Draft recommendations for aspirin to prevent cardiovascular disease 2021. Accessed December 28, 2021 at: https://www.uspreventiveservicestaskforce.org/ uspstf/sites/default/files/file/supporting_documents/aspirin-cvd-prevention-final-rec-bulletin.pdf

3 Patrono C, Baigent C. Role of aspirin in primary prevention of cardiovascular disease. Nat Rev Cardiol 2019;16(11):675-686

4 Schrör K, Kristensen SD, Storey RF, Verheugt FWA. Aspirin and primary prevention in patients with diabetes-a critical evaluation of available randomized trials and meta-analyses. Thromb Haemost 2019;119(10):1573-1582

5 De Caterina R, Aimo A, Ridker PM. Aspirin therapy for primary prevention: the case for continuing prescribing to patients at high cardiovascular risk-a review. Thromb Haemost 2020;120(02): 199-206

6 Cleland JG. Is aspirin useful in primary prevention? Eur Heart J 2013;34(44):3412-3418

7 Cleland JG. Is aspirin "the weakest link" in cardiovascular prophylaxis? The surprising lack of evidence supporting the use of aspirin for cardiovascular disease. Prog Cardiovasc Dis 2002;44 (04):275-292

8 Cleland JGF. Physicians addicted to prescribing aspirin-a disorder of cardiologists (PAPA-DOC) syndrome: the headache of nonevidence-based medicine for ischemic heart disease? JACC Heart Fail 2018;6(02):168-171

9 Cleland JGF. Chronic aspirin therapy for the prevention of cardiovascular events: a waste of time, or worse? Nat Clin Pract Cardiovasc Med 2006;3(05):234-235

10 Cleland JG. Chronic aspirin is effective-if data are massaged sufficiently. BMJ 2002;324(7332):295

11 Cleland JG. Systematic reporting bias in meta-analyses of trials of aspirin for the primary prevention of cardiovascular disease. Am J Med 2012;125(02):e13

12 Calderone D, Greco A, Ingala S, et al. Efficacy and safety of aspirin for cardiovascular risk prevention in younger and older age: an updated systematic review and meta-analysis. Thromb Haemost 2021. Doi: 10.1055/a-1667-7427

13 Yusuf S, Joseph P, Dans A, et al; International Polycap Study 3 Investigators. Polypill with or without aspirin in persons without cardiovascular disease. N Engl J Med 2021;384(03):216-228

14 Acharya T, Aspelund T, Jonasson TF, et al. Association of unrecognized myocardial infarction with long-term outcomes in community-dwelling older adults: the ICELAND MI study. JAMA Cardiol 2018;3(11):1101-1106

15 McAreavey D, Vidal JS, Aspelund T, et al. Midlife cardiovascular risk factors and late-life unrecognized and recognized myocardial infarction detect by cardiac magnetic resonance: ICELAND-MI, the AGES-Reykjavik study. J Am Heart Assoc 2016;5(02):e002420

16 Sigurdsson S, Aspelund T, Kjartansson O, et al. Incidence of brain infarcts, cognitive change, and risk of dementia in the general population: the AGES-Reykjavik Study (Age Gene/Environment Susceptibility-Reykjavik Study). Stroke 2017;48(09):2353-2360

17 Bowker TJ, Wood DA, Davies MJ, et al. Sudden, unexpected cardiac or unexplained death in England: a national survey. QJM 2003;96 (04):269-279

18 Morant SV, McMahon AD, Cleland JG, Davey PG, MacDonald TM. Cardiovascular prophylaxis with aspirin: costs of supply and management of upper gastrointestinal and renal toxicity. $\mathrm{Br} \mathrm{J}$ Clin Pharmacol 2004;57(02):188-198

19 Cleland JG. Long-term aspirin for coronary artery disease: are we being deceived by a biased presentation of the evidence? Future Cardiol 2010;6(02):141-146 
20 Baigent C, Collins R, Appleby P, Parish S, Sleight P, Peto R. ISIS-2: 10 year survival among patients with suspected acute myocardial infarction in randomised comparison of intravenous streptokinase, oral aspirin, both, or neither. The ISIS-2 (Second International Study of Infarct Survival) Collaborative Group. BMJ 1998; 316(7141):1337-1343

21 First International Study of Infarct Survival Collaborative Group. Randomised trial of intravenous atenolol among 16027 cases of suspected acute myocardial infarction: ISIS-1. Lancet 1986;2 (8498):57-66

22 Rothwell PM, Algra A, Chen Z, Diener HC, Norrving B, Mehta Z. Effects of aspirin on risk and severity of early recurrent stroke after transient ischaemic attack and ischaemic stroke: timecourse analysis of randomised trials. Lancet 2016;388 (10042):365-375

23 Aspirin Myocardial Infarction Study Research Group. A randomized, controlled trial of aspirin in persons recovered from myocardial infarction. JAMA 1980;243(07):661-669
24 Juul-Möller S, Edvardsson N, Jahnmatz B, Rosén A, Sørensen S, Omblus RThe Swedish Angina Pectoris Aspirin Trial (SAPAT) Group. Double-blind trial of aspirin in primary prevention of myocardial infarction in patients with stable chronic angina pectoris. Lancet 1992;340(8833):1421-1425

25 Farrell B, Godwin J, Richards S, Warlow CUK-TIA Study Group. The United Kingdom transient ischaemic attack (UK-TIA) aspirin trial: final results. J Neurol Neurosurg Psychiatry 1991;54(12): 1044-1054

26 Davie AP, Love MP, McMurray JJ. Even low-dose aspirin inhibits arachidonic acid-induced vasodilation in heart failure. Clin Pharmacol Ther 2000;67(05):530-537

27 CAPRIE Steering Committee. A randomised, blinded, trial of clopidogrel versus aspirin in patients at risk of ischaemic events (CAPRIE). Lancet 1996;348(9038):1329-1339

28 Eikelboom JW, Connolly SJ, Bosch J, et al; COMPASS Investigators. Rivaroxaban with or without aspirin in stable cardiovascular disease. N Engl J Med 2017;377(14):1319-1330 